\title{
Credit Constraint Exports in Countries with Different Degrees of Contract Enforcement
}

\author{
Zi-Yi Guo (Corresponding author) \\ Corporate Model Risk Management Group, Wells Fargo Bank \\ N.A., 301 S College St, Charlotte, NC 28202, United States \\ E-mail: zachguo0824@gmail.com
}

Yangxiaoteng Luo

Department of Finance, Kellstadt Graduate School of Business

Depaul University, 1 E. Jackson Blvd., Chicago, IL 60604, United States

E-mail:yxtluo@gmail.com

Received: March 13, 2017 Accepted: April 19, 2017

doi:10.5296/ber.v7i1.10923 URL: https://doi.org/10.5296/ber.v7i1.10923

\begin{abstract}
We theoretically consider firms' export decisions in a heterogeneous firm framework. The paper assumes firms have idiosyncratic productivity levels and are credit-constrained in the export market. Firms in different countries have different degrees of credit constraints. Because of imperfect financial markets, firms might not be able to get the financial support to export even although they are profitable enough from the foreign market. In a country with strong contract enforcement, firms are more likely to export and export to more destinations; while in a country with weak contract enforcement, firms are more likely to be constrained by liquidity and export to fewer destinations. However, for those firms whose productivity is very low or very high, these influences do not exist. Moreover, we consider technology shocks and illustrate that technology shocks will further impede firms' export decisions.
\end{abstract}

Keywords: Heterogeneous firms; Export decisions; Technology shocks

JEL classifications: D21; F12; G14

\section{Introduction}

There are increasing literatures demonstrating that firms' export actions are not only 
influenced by their productivity levels, but also influenced by their credit constraints (see Wagner, 2014, for a survey). Intuitively, firms in different countries with different degrees of contract enforcement should have different credit constraints. So, what are the differences of their export actions in different countries? This paper aims to build an international trade model with heterogeneous firms to theoretically analyze the differences.

As mentioned by many empirical papers, firms face a huge sunk cost to export. A non-exhaustive list includes: Bellone, Musso, Nesta and Schiavo (2010), Minetti and Zhu (2011), Caggese and Cunat (2013), Manova (2013), Besedes, Kim and Lugovskyy (2014), Wagner (2014), Manova, Wei and Zhang (2015), and Hasan and Sheldon (2016). In my model, the huge sunk cost has two channels of influence to the firms. First, to cover the huge sunk cost, firms must raise enough credit besides using their domestic profits. In a country with strong contract enforcement, firms are more likely to raise the required credit, because in those countries once firms default, creditors can receive more collateral so they have a stronger motivation to lend. In contrast, in a country with weak contract enforcement, firms are harder to raise the credit because the incentives to lend for creditors in those countries are weaker. Because firms are more likely to raise enough credit in a country with strong contract enforcement, those firms with certain level of productivity may be easier to become exporters. However, if their productivity levels are too low or too high, this influence does not exist. Second, if we consider technology shocks, firms may lose money in business in some temporary difficult situations. Because of the huge re-enter cost, firms may be sensitive for their failure and more conservative to use their credit to distribute dividend in the regular situations and hold larger cash flows to elude firms' failure. In a country with strong contract enforcement, because firms are easier to raise credit to elude the risk of failure when they are in the temporary difficult situations, they will distribute more with less cash in hand and export more aggressively than those in a country with weak contract enforcement.

Chaney (2016) extends Melitz's (2003) heterogeneous firms model and adds a consideration of liquidity constraint. In his model, firms must pay the sunk cost of export before they become exporters. To cover the sunk cost, firms can use their profits from the domestic market or from some additional exogenous liquidity shocks. Chaney does find that a set of firms could profitably export, but they are prevented from doing so because they lack sufficient liquidity. Manova (2013) argues that credit constraints interact with firm productivity, thus reinforcing the way those firms with higher productivity select into exporting. Manova further finds empirical evidence to support her argument. Similarly, Muuls (2015) builds a heterogeneous firms model of international trade with liquidity-constrained firms, and finds that credit constraints are important in determining the extensive but not the intensive margin of trade in terms of destinations. Although these papers all analyze the relationship between firms' export actions and credit constraints, they do not consider the difference of credit constraints in different countries, and on the other hand, they are all in a static framework.

This paper assumes the credit market is imperfect, and the degrees of imperfection in different countries are different. There are some related papers analyzing firms' performance in different countries with different degrees of contract enforcement. Arellano, Bai and Zhang 
(2012) build a dynamic model to explain the relationship between contract enforcement and firms' financing. They find that in a country with weak contract enforcement smaller firms use debt to finance more conservative than in a country with strong contract enforcement, but this difference does not exist for larger firms. Bond, Tybout and Utar (2008) use panel data on Colombian apparel producers and show that an efficient credit market would improve the weighted-average efficiency of producers by about 5 percent. My model aims to explain the relationship between contract enforcement and international trade, and also tries to show an efficient credit market would induce more firms to export and then increase the international trade.

When we consider the risk of international trade, intuitively the foreign market will have more risk than the domestic market. At the same time, foreign market requires a larger sunk cost, so intuitively they will use debt more conservative because once firms fail in the foreign market the reenter cost is very high. Campa and Shaver (2002) use the Spanish manufacturing sector data from 1990 to 1998 and suggest that exporters' cash flows and capital investment are more stable than non-exporters. Furthermore, they find that liquidity constraints are less binding for exporters than for non-exporters. In this paper, I want to provide some insights to discuss possible explanations in an international trade model with heterogeneous firms with technology shocks.

The remainder of the paper is organized as follows. Section 2 describes the model without technology shocks. Section 3 discusses the main model results. A possible extension with technology shocks is in Section 4. Section 5 concludes.

\section{The Model}

In this section I will extend Melitz's (2003) heterogeneous firms model of international trade and consider a simple case without technology shocks. The model is similar as in Manova (2013), Muuls (2015) and Chaney (2016), but I consider it from different perspectives.

In the model, the economy consists of two countries Home and Foreign (the latter is hereafter denoted with an asterisk*). The only factor of production is labor, and the population is of size $L$. There are two sectors. One sector provides a single homogeneous good which is freely traded. This good is used as the numeraire, and its price is equal to 1. Production in this sector is characterized by constant returns to scale with $q_{0}=B \times l_{0}, l_{0}$ being the labor used to produce quantity $q_{0}$ of the good. By choice of scale, the unit labor requirement at home is $1 / \omega(B=\omega)$ and $1 / \omega^{*}$ in foreign $\left(B^{*}=\omega^{*}\right)$. Therefore, as shall be assumed, if both countries produce the homogeneous good, wages will be fixed by this sector's production at $\omega$ and $\omega^{*}$ respectively. The second sector produces a continuum of differentiated goods. Each firm operating in this sector supplies one of these goods and is a monopolist for its variety. 


\section{Macrothink}

Business and Economic Research

ISSN 2162-4860 2017, Vol. 7, No. 1

\subsection{Demand}

Consumers are endowed with one unit of labor and their preferences over the differentiated good display a constant elasticity of substitution (CES). Given their preference of variety, they will consume all available varieties. The utility function of the representative consumer can be represented by $U$ :

$$
U \equiv q_{0}^{1-\mu}\left(\int_{\omega \in \Omega} q(\omega)^{\frac{\sigma-1}{\sigma}} d \omega\right)^{\frac{\sigma}{\sigma-1} \mu}
$$

with $\sigma>1$ and $1>\mu>0$. The utility level is determined by the consumption of $q_{0}$ units of the homogeneous good and $q(\omega)$ units of each variety $\omega$ of the differentiated good. The representative consumer's income is $\omega$ and the consumer maximizes his utility. The demand for the each differentiated good is:

$$
q(\omega)=\mu \omega L\left(\frac{p(\omega)^{-\sigma}}{P}\right) .
$$

The price index for differentiated goods domestically is $P$ :

$$
P=\left(\int_{\omega \in \Omega} p(\omega)^{1-\sigma} d \omega\right)^{\frac{1}{1-\sigma}}
$$

The total expenditures of all consumers for each variety $\omega$ is $r(\omega)$, as:

$$
r(\omega)=\mu \omega L\left(\frac{p(\omega)^{-\sigma}}{P^{1-\sigma}}\right) .
$$

\subsection{Production}

For each variety $\omega$, there are a lot of heterogeneous firms to produce it. These firms are differentiated by their productivity level $x$. For a typical firm with productivity level $x$, the cost function for domestic market is $c_{d}\left(q_{d}\right)$ :

$$
c_{d}\left(q_{d}\right)=q_{d} \frac{\omega}{x}+\omega C_{d}
$$

with $C_{d}$ denoting the sunk cost.

To become an exporter, a firm must pay a variable "iceberg" transport cost and a huge sunk 
cost $C_{f}$. The cost function for its foreign market is $c_{f}\left(q_{f}\right)$ :

$$
c_{f}\left(q_{f}\right)=q_{f} \frac{\tau \omega}{x}+\omega^{*} C_{f}
$$

With monopolistic competition, firms have a power to make their prices in both domestic market and foreign market. The optimal prices for domestic market and foreign market are $p_{d}(x)$ and $p_{f}(x)$ respectively. As:

$$
p_{d}(x)=\frac{\sigma}{\sigma-1} \times \frac{\omega}{x}, \text { and } p_{f}(x)=\frac{\sigma}{\sigma-1} \times \frac{\tau \omega}{x}
$$

The profit functions for domestic market and foreign market are $\pi_{d}(x)$ and $\pi_{f}(x)$ respectively. As:

$$
\pi_{d}(x)=\frac{r_{d}(x)}{\sigma}-\omega C_{d}=\frac{\mu}{\sigma} \omega L\left(\frac{\sigma}{\sigma-1} \times \frac{\omega}{x P}\right)^{1-\sigma}-\omega C_{d},
$$

and

$$
\pi_{f}(x)=\frac{r_{f}(x)}{\sigma}-\omega C_{f}=\frac{\mu}{\sigma} \omega^{*} L^{*}\left(\frac{\sigma}{\sigma-1} \times \frac{\tau \omega}{x P^{*}}\right)^{1-\sigma}-\omega^{*} C_{f} .
$$

When there is no credit constraint, the threshold values for firms to enter domestic market and to export are $\bar{x}_{d}$ and $\bar{x}_{f}$ respectively, such that $\pi_{d}\left(\bar{x}_{d}\right)=0$ and $\pi_{f}\left(\bar{x}_{f}\right)=0$. These are the main results of Melitz (2003). When a firm's productivity level is below $\bar{x}_{d}$, it will not enter the domestic market and only when its productivity level is above $\bar{x}_{f}$, it will begin to export.

\section{Main Results}

\subsection{Firms 'Actions with Liquidity Constraints}

In the setting above, exporting involves fixed costs. In reality, these must mostly paid before any profits are made abroad. If financial markets are imperfect, this will lead to ex-ante under-investment in exporting activities. A different nature of contracting and informational environment in Foreign implies that this is more the case than for domestic entry costs. Foreign activities are less verifiable and are considered more risky, as they involve, for example, the use of a foreign currency. The weak contracting environment in some foreign countries means it is harder to recover unpaid dues abroad, and therefore firms are unable to 
pledge as much collateral for exports. These different elements mean that potential investors or lenders may not be willing to help would-be exporters cover the fixed cost of starting to export.

For simplicity, in the model, I assume that there is no liquidity or credit constraint for firms to finance their domestic production. In the first step, firms can finance the variable cost of exporting internally. The sunk cost of exporting is assumed to be financed in three different ways. First, a firm can use the profits generated from domestic sales $\pi_{d}(x)$. Second, each firm is endowed with an exogenous random liquidity shock $A$, denominated in units of domestic labor. Its value is hence $\omega A$. Third, a firm can decide to borrow an amount $E$ on financial markets. In order to do so, it must pledge tangible assets as collateral, and it is assumed that these will be proportional to the sunk cost paid to enter the domestic market (we assume firms cannot use the fixed cost from foreign market as collateral. The proportionality $t_{s}$ is different across countries. The creditors can receive a repayment of $G(x)$ if firms do not default, and $t_{s} \omega C_{d}$ if firm default. In a country with strong contract enforcement, if firms default, the creditors are more likely to receive more collateral and therefore $t_{s}$ is larger. However in a country with weak contract enforcement, once firms default, the creditors are harder to receive their collateral and therefore $t_{s}$ is smaller. I call $t_{s}$ the index of the degree of contract enforcement. For simplicity, I also assume that the default rate is exogenous and equals to $\lambda$.

Given these three possibilities for financing the sunk cost of exporting, the liquidity constraint can be expressed as: $\omega A+\pi_{d}(x)+E \geq \omega^{*} C_{f}$. A higher domestic profit therefore relaxes the firm's credit constraint. The firm needs to borrow $k \omega^{*} C_{f}$ to cover the fixed cost of exporting, by defining the share $(1-k)$ of this cost that can be covered internally by the firm such that $(1-k) \omega^{*} C_{f}=\omega A+\pi_{d}(x)$. As domestic profit increases, $k$ decreases and the firm is less credit-constrained. Exporters choose their price and output levels for foreign by maximizing profits on the foreign market. The exporter's problem is:

$$
\pi_{f}(x)=p_{f}(x) q_{f}(x)-\frac{q_{f}(x) \tau \omega}{x}-(1-k) \omega^{*} C_{f}-\lambda G(x)-(1-\lambda) t_{s} \omega C_{d}
$$

subject to

$$
q_{f}(x)=\mu \omega^{*} L^{*} \frac{p_{f}(x)^{-\sigma}}{P^{* 1-\sigma}}
$$




$$
\begin{gathered}
N R(x)=p_{f}(x) q_{f}(x)-\frac{q_{f}(x) \tau \omega}{x}-(1-k) \omega^{*} C_{f} \geq G(x) \\
B(x)=\lambda G(x)+(1-\lambda) t_{s} \omega C_{d}-k \omega^{*} C_{f} \geq 0
\end{gathered}
$$

There are three constraints to this maximization problem. The first condition arises even without imperfect financial markets, as it represents the demand condition. The second condition reflects that the maximum net revenues $N R(x)$ the firm can offer to the creditors.

The third condition expresses the net return to the investor $B(x)$ being positive (I assume that the creditors are risk-natural).

If there is no credit constraint, the threshold value for firms to become exporters:

$$
\bar{x}_{f}=\left(\frac{\sigma C_{f}}{\mu L^{*}}\right)^{\frac{1}{\sigma-1}} \frac{1}{\sigma-1} \frac{\tau \omega}{P^{*}} .
$$

As credit markets are competitive, all investors break even and have zero expected profits. Firms choose $G(x)$ so as to bring the investor to his participation constraint. $B(x)=0$ in equilibrium. So if there is credit constraint, the threshold value for firms to choose export is:

$$
\bar{x}(A)=\omega \frac{\sigma}{\sigma-1}\left(\frac{\sigma}{\mu}\right)^{\left(\frac{1}{\sigma-1}\right)}\left[\frac{1}{\lambda} \omega^{*} C_{f}-\frac{1-\lambda}{\lambda}\left(t_{s}-1\right) \omega C_{d}-\frac{1-\lambda}{\lambda} \omega A\right]^{\frac{1}{\sigma-1}} \times\left[\omega^{*} L^{*}\left(\frac{\tau}{P^{*}}\right)^{1-\sigma}+\frac{1-\lambda}{\lambda} \omega L\left(\frac{1}{P}\right)^{1-\sigma}\right]^{\frac{1}{1-\sigma}} .
$$

Define $h\left(C_{d}\right)$ as:

$$
h\left(C_{d}\right)=\frac{\sigma}{\sigma-1} \frac{\omega}{P}\left(\frac{\sigma C_{d}}{\mu L}\right)^{\frac{1}{\sigma-1}}
$$

Proposition 1: If $\left[\frac{C_{d}^{*}}{C_{f}} \frac{(1-\lambda)\left(1-t_{s}\right) C_{d}+\frac{\omega^{*}}{\omega} C_{f}}{\lambda \tau^{1-\sigma}\left(\frac{\omega^{*}}{\omega}\right)^{\sigma}+(1-\lambda)\left(\frac{h\left(C_{d}\right)}{h\left(C_{f}^{*}\right)}\right)^{1-\sigma} C_{d}}\right]>\frac{\tau \omega}{\omega^{*}}$, there is non-empty set of credit-constrained firms that are prevented from profitably exporting because they have insufficient liquidity, both exogenously and on the external financial market.

The model so far does not compare firms' export actions across countries. In the following, I consider the firms' export actions in different countries with different degrees of contract enforcement. 


\subsection{Firms' Export Actions in Different Countries}

The creditors lend credit to the firms and receive repayment if firms do not default. In a country with strong contract enforcement, the creditors can receive more collateral once firms default, while in a country with weak contract enforcement they may receive much less collateral. Suppose the density function of the exogenous random liquidity shock is: $A \sim g(A)$, so the probability to export for producers with productivity $x$ is:

$$
\begin{aligned}
& p(x \geq \bar{x}(A))=p(A \geq \frac{\lambda}{(1-\lambda) \omega}\left\{-\frac{1-\lambda}{\lambda}\left(t_{s}-1\right) \omega C_{d}+\frac{1}{\lambda} \omega^{*} C_{f}-\right. \\
&\left.\left.\left(\frac{x}{\omega} \frac{\sigma-1}{\sigma}\right)^{\sigma-1} \frac{\mu}{\sigma}\left[\omega^{*} L^{*}\left(\frac{\tau}{P^{*}}\right)^{1-\sigma}+\frac{1-\lambda}{\lambda} \omega L \frac{1}{P^{1-\sigma}}\right]\right\}\right),
\end{aligned}
$$

where $x \in\left[\bar{x}_{f}, \bar{x}(0)\right]$. Furthermore, we can conclude:

$$
\frac{\partial}{\partial t_{s}}(p(x \geq \bar{x}(A)))>0
$$

Proposition 2: When the conditions in Proposition 1 hold, if a firm's productivity level $x \in\left[\bar{x}_{f}, \bar{x}(0)\right]$, whether it will choose to export or not depends on the exogenous liquidity shock. In a country with strong contract enforcement, producers are more likely to export; in contrast, in a country with weak contract enforcement, producers are less likely to export. However, for those firms whose productivity levels are too high or too low, they will not be affected.

When a firm's productivity level is too low $\left(x<\bar{x}_{f}\right)$, the firm cannot gain profits from exporting, so it will not choose to export. But when a firm's productivity level is very high $(x>\bar{x}(0))$, firms can use their domestic profits to cover all the pre-paid sunk cost of exporting, so the credit constraints does not exist for them.

Figure 1 illustrates the idea of Proposition 2. As one can see, when a firm's productivity reaches to a level of $\bar{x}(0)$, they will export regardless of which country they are residing in. However, if their productivity is in the range of $x \in\left[\bar{x}_{f}, \bar{x}(0)\right]$, the influence is significant. 


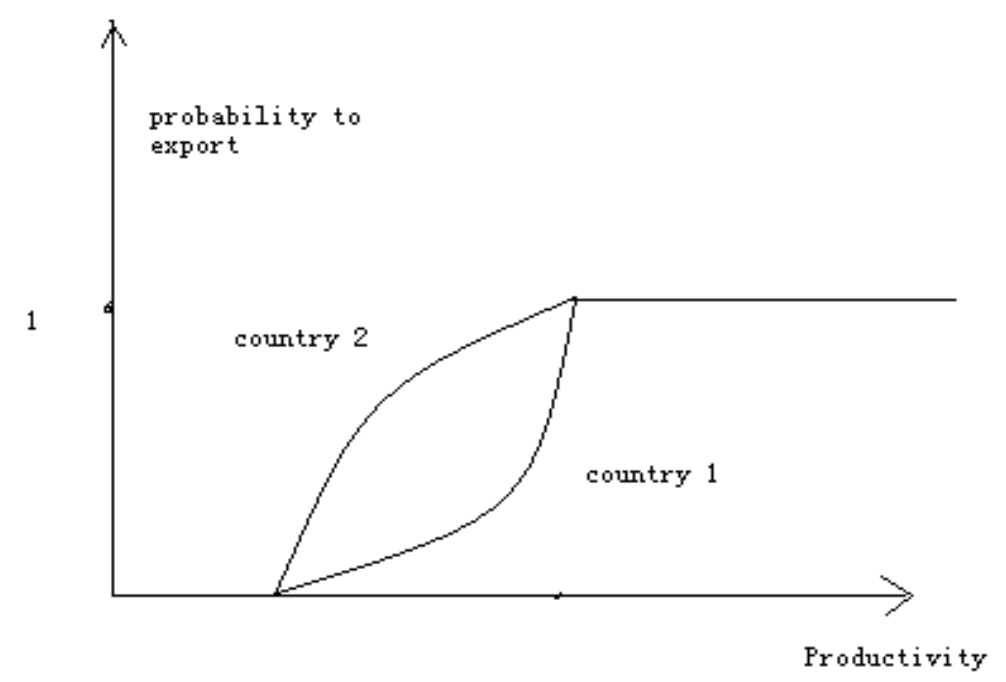

Figure 1. Firms' export decisions

\subsection{Destinations}

In this subsection, the model is extended to the case in which there are more than two countries and each firm in Home can decide to export to more than one destination. In this case, it needs to pay the fixed cost exporting to each of the destinations it serves. Without credit constraints, all destinations to which a firm could profitably export are served. However, with credit market imperfections, a firm which has limited available liquidity will only be able to pay the sunk cost of exporting to a certain number of countries. On the external financing side, if a firm decides to export $n$ destinations, then the available collateral for each destination will be $\frac{t_{s} \omega C_{d}}{n}$. The exogenous liquidity and domestic profits available for covering the sunk cost of serving each destination will be also divided by $n$. With similar analysis, the productivity threshold value for exporting to $n$ countries is:

$$
\begin{aligned}
& \bar{x}_{n}(A)=\omega \frac{\sigma}{\sigma-1}\left(\frac{\sigma}{\mu}\right)^{\frac{1}{\sigma-1}}\left[\frac{1}{\lambda} \omega^{*} C_{f}-\frac{1-\lambda}{\lambda}\left(\frac{t_{s}}{n}-1\right) \omega C_{d}-\frac{1-\lambda}{\lambda} \frac{\omega A}{n}\right]^{\frac{1}{\sigma-1}} \times \\
& {\left[\omega^{*} L^{*}\left(\frac{\tau}{P^{*}}\right)^{1-\sigma}+\frac{1-\lambda}{\lambda} \omega \frac{L}{n}\left(\frac{1}{P}\right)^{1-\sigma}\right]^{\frac{1}{1-\sigma}} . }
\end{aligned}
$$

So:

$$
\begin{aligned}
n=\left\{-\left(\frac{x}{\omega} \frac{\sigma-1}{\sigma}\right)^{\sigma-1}\right. & \left.\frac{\mu}{\sigma} \omega^{*} L^{*}\left(\frac{\tau}{P^{*}}\right)^{1-\sigma}-\frac{1}{\lambda} \omega^{*} C_{f}+\frac{1-\lambda}{\lambda} \omega C_{d}\right\}^{-1} \times \\
& \left\{\frac{1-\lambda}{\lambda} t_{s} \omega C_{d}+\frac{1-\lambda}{\lambda} \omega A+\frac{1-\lambda}{\lambda}\left(\frac{x}{\omega} \frac{\sigma-1}{\sigma}\right)^{\sigma-1} \frac{\mu}{\sigma} \omega L\left(\frac{1}{P}\right)^{1-\sigma}\right\} .
\end{aligned}
$$


Furthermore, $\frac{\partial}{\partial t_{s}}(n)>0$, so if firms face the same exogenous credit shock $A$, in a country with strong contract enforcement, they can export to more countries, while in a country with weak contract enforcement, the number of destinations is constrained more. The probability to export to more than $n_{0}$ countries:

$$
\begin{aligned}
p\left(n \geq n_{0}\right)=p\left(A \geq \frac{\lambda}{(1-\lambda) \omega}\left\{n_{0}\right.\right. & {\left[-\left(\frac{x}{\omega} \frac{\sigma-1}{\sigma}\right)^{\sigma-1} \frac{\mu}{\sigma} \omega^{*} L^{*}\left(\frac{\tau}{P^{*}}\right)^{1-\sigma}-\frac{1}{\lambda} \omega^{*} C_{f}+\frac{1-\lambda}{\lambda} \omega C_{d}\right] } \\
& \left.\left.-\left[\frac{1-\lambda}{\lambda} t_{s} \omega C_{d}+\frac{1-\lambda}{\lambda}\left(\frac{x}{\omega} \frac{\sigma-1}{\sigma}\right)^{\sigma-1} \frac{\mu}{\sigma} \omega L\left(\frac{1}{P}\right)^{1-\sigma}\right]\right\}\right) .
\end{aligned}
$$

Then:

$$
\frac{\partial}{\partial t_{s}}\left(p\left(n \geq n_{0}\right)\right)>0
$$

Proposition 3: In a country with strong contract enforcement, producers are more likely to export more destinations than in a country with weak contract enforcement.

The figure below describes the different probabilities to export to $n$ destinations in two different countries with different contract enforcement. Similarly, when a firm's productivity reaches to a level of $\bar{x}(0)^{\prime}$, they will export to $N$ destinations regardless of which country they are residing in. However, if their productivity is in the range of $x \in\left[\bar{x}_{f}, \bar{x}(0)\right]$, the influence is significant.

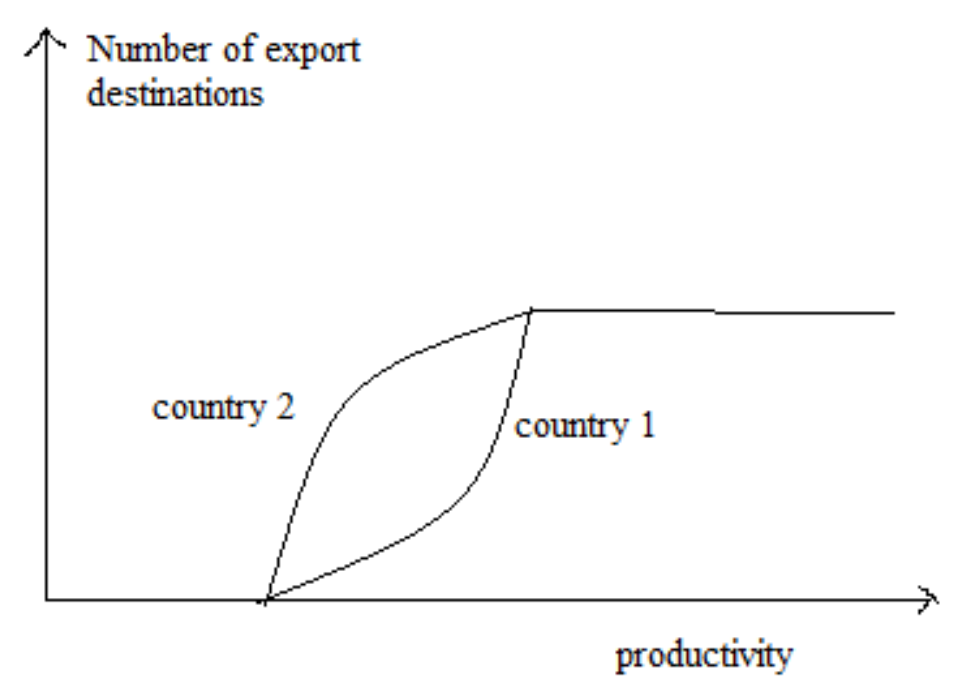

Figure 2: Firms' multinational export behaviors 


\section{Extensions}

In this section, I extend the model with technology shocks. In the previous model, firms' productivity levels are constant. Firms choose to export at the beginning, and then their export statuses are exogenous. However, in reality, firms may face technology shocks, which means firms may lose money in business in some temporary situations. I call these situations firms "bad time". These shocks are more significant for those firms whose productivities are very close to the threshold value of exporting or entering the market, because firms whose productivities are much higher than the threshold value may still be profitable even during the bad time. I assume firms cannot borrow credit on the foreign market (Intuitively, the creditors may trust domestic firms more than foreign firms) and they only can borrow credit on the domestic market. In a country with a more perfect financial market, firms are easier to get access to credit when they are in a temporary bad time, and therefore they are more likely to survive during that time. However, in a country with less perfect financial market, it is more likely that firms fail to borrow credit even though they are really very profitable from a long-run view. Therefore, to avoid failure, firms may reserve some liquidity for some temporary risks and reduce their distribution of dividend. In the country with more perfect financial market, one might be able to see more firms enter the domestic market and more firms choose to export, and in the contrast in the country with less perfect financial market, more firms will not choose to export because they worry more about their failure.

\subsection{Entrepreneurs'Actions without External Finance}

The model is extended on Melitz's (2003) heterogeneous firms' model. In the model, there are a lot of heterogeneous entrepreneurs, and each entrepreneur owns a special productivity level. For a typical entrepreneur with productivity level $x$, once he or she enter the market, the productivity level of his or her firm will be $x$. Firms do not only face a sunk $\operatorname{cost} C_{s}$, but also face a fixed management $\operatorname{cost} C_{m}$. At each period, there exists a i.i.d. technology shock $z_{t}(t=0,1, \cdots,+\infty)$, so their profit functions are at period $t$ :

$$
\pi_{t}\left(x, z_{t}\right)=\frac{r_{t}\left(x, z_{t}\right)}{\sigma}-\omega C_{m}=\frac{\mu}{\sigma} \omega L\left(\frac{\sigma}{\sigma-1} \times \frac{z_{t} \omega}{x P}\right)^{1-\sigma}-\omega C_{m} .
$$

The entrepreneur gains utility exclusively from consumption and his or her income comes from his or her firm's profit and does not work. The utility function is:

$$
u(C)=\frac{C^{1-\gamma}}{1-\gamma}, C \geq 0 .
$$

If there is no technology shock, one can solve the threshold value of entrepreneurs' productivity level $\bar{x}_{0}$ to enter the domestic market. As: 


$$
\sum_{t=0}^{+\infty} \beta^{t} \frac{\left(\pi_{t}\left(\bar{x}_{0}, 1\right)\right)^{1-\gamma}}{1-\gamma}=\frac{C_{s}^{1-\gamma}}{1-\gamma}
$$

where $\beta>0$ is the discount rate. At each period, the entrepreneur uses all the profit for consumption. If there exists technology shocks and the entrepreneur with productivity level $x$ enters the market, the entrepreneur's problem becomes:

$$
V^{c}(x)=E\left\{\sum_{t=0}^{+\infty} \beta^{t} \frac{C_{t}^{1-\gamma}\left(\prod_{s=0}^{t} 1\left(R_{s} \geq 0\right)\right)}{1-\gamma}\right\}
$$

subject to:

$$
C_{t}+R_{t+1}=\pi_{t}\left(x, z_{t}\right)+(1+\theta) R_{t}, \text { and } C_{t} \geq 0,
$$

where $\theta$ is interest rate and $R_{t}$ is the cash flow the entrepreneur holds at period $t$. The entrepreneur's choice is: entry if $V^{c} \geq u\left(C_{s}\right)$; otherwise not entry.

If there are technology shocks, the entrepreneur will not consume all his profits and hold some cash for eluding the risk of his firm's failure, because once his firm loses money in business, and at the same time he does not have a reserve to cover the loss (wither incomplete financial market here I consider there is no external finance), his firm will die. If his firm dies, the only way for him to gain the profits is re-entering the market, which means he has to pay the huge sunk cost again. Intuitively, those entrepreneurs who choose to enter the market usually will consider the failure of their firms before they enter. If there exists technology shocks, some less productive firms which are profitable when there is no technology shock will leave from the export market. To elude the potential failure in the export market and paying for the cost of re-entering the export market, firms will hold more reserve and export more conservative.

Figure 3 illustrates firms' export decision when they face both credit and technology uncertainty. With technology shocks and the huge sunk cost, firms' export decisions become even more conservative since they will demand higher profits to endure the possible failure in the export market. 


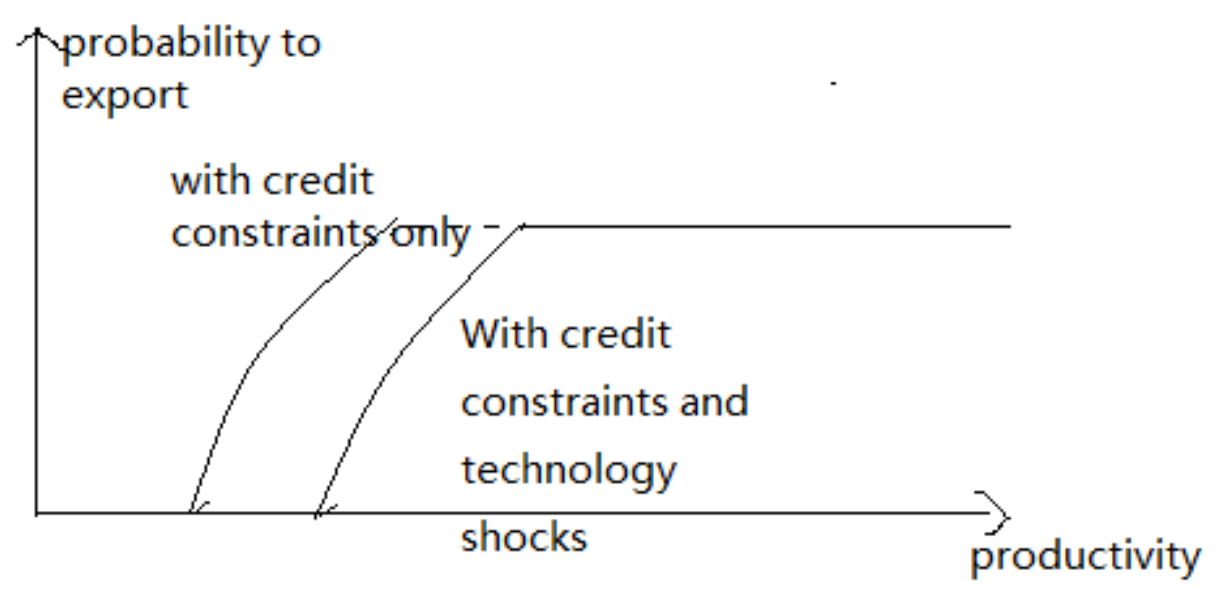

Figure 3. Firms' export decisions with technology shocks

\section{Conclusion}

In this paper, I construct an international trade model and consider firms' export actions in different environments with different degrees of contract enforcement. Firms must pay the sunk cost before exporting. Because of imperfect financial markets, firms might not be able to get the credit to export even although they are profitable enough from the foreign market. In a country with strong contract enforcement, firms are more likely to export and then export to more destinations; while in a country with weak contract enforcement, firms are more likely to be constrained by liquidity and export to fewer destinations. However, for those firms whose productivity is very low or very high, these influences do not exist.

Then I consider firms' export actions in a dynamic framework. In this framework, firms' productivity levels are not constant, but influenced by some technology shocks. Because of technology shocks, firms may lose money in business in some temporary adverse situations, so they need some temporary credit to pass those negative technology shocks. If there is no external finance, firms will hold some liquidity to elude the failure and some less productive firms will leave the foreign market which aggravates the reallocation effect. In other words, firms become more conservative in their export behaviors.

There might be several directions for future research. First, in the model the degree of contract enforcement is exogenous. As mention in Arellano, Bai and Zhang (2012) different sizes of firms have different forms of financing. It might be interesting if we assume the degree of contract enforcement to be endogenous. Second, the paper discusses firms' export behaviors purely in a theoretical framework. It would be beneficial if one could further provide empirical evidences to support the model results. Finally, the model assumes perfect information, which is far away from the reality. Intuitively, firms are endowed much more domestic information than foreign information. It would be interesting to assume firms have asymmetric information as in Guo (2017) to discuss how information imperfection affects firms' export decisions. 


\section{References}

Arellano, C., Bai, Y., \& Zhang, J. (2012). Firm Dynamics and Financial Development. Journal of Monetary Economics, 59, 533-549. https://doi.org/10.1016/j.jmoneco.2012.06.006

Bellone, F., Musso, P., Nesta, L., \& Schiavo, S. (2010). Financial Constraints and Firm Export Behavior. World Economy, 33, 347-373.

https://doi.org/10.1111/j.1467-9701.2010.01259.x

Besedes, T., Kim, B., \& Lugovskyy, V. (2014). Export Growth and Credit Constraints. European Economic Review, 70, 350-370. https://doi.org/10.1016/j.euroecorev.2014.05.001

Bond, E., Tybout, J., \& Utar, H. (2008). Credit Rationing, Macro Volatility, and Industrial Evolution in Developing Countries. Working Paper, NBER.

Caggese, A., \& Cunat, V. (2013). Financing Constraints, Firm Dynamics, Export Decisions, and Aggregate Productivity. Review of Economic Dynamics, 16, 177-193. https://doi.org/10.1016/j.red.2012.10.004

Campa, J., \& Shaver, M. (2002). Exporting and Capital Investment: On the Strategic Behavior of Exporters. Working Paper, IESE Business School, University of Navarra.

Chaney, T. (2016). Liquidity Constrained Exporters. Journal of Economic Dynamics and Control, 72, 141-154. https://doi.org/10.1016/j.jedc.2016.03.010

Feenstra, R., Li, Z., \& Yu, M. (2014). Exports and Credit Constraints under Incomplete Information: Theory and Evidence from China. Review of Economics and Statistics, 96, 729-744. https://doi.org/10.1162/REST_a_00405

Guo, Z. (2017). Noisy Information, Risk Sharing and International Real Business Cycles. Mimeo.

Hasan, S., \& Sheldon, I. (2016). Credit Constraints, Technology Choice and Exports: A Firm-level Study for Latin American Countries. Review of Development Economics, 20, 547-570. https://doi.org/10.1111/rode.12248

Manova, K. (2013). Credit Constraints, Heterogeneous Firms and International Trade. Review of Economic Studies, 81, 711-744. https://doi.org/10.1093/restud/rds036

Manova, K., Wei, S., \& Zhang, S. (2015). Firm Exports and Multinational Activity under Credit Constraints, Review of Economics and Statistics, 77, 574-588.

https://doi.org/10.1162/REST_a_00480

Melitz, M. (2003). The Impact of Trade on Intra-industry Reallocations and Aggregate Industry Productivity. Econometrica, 71, 71-106. https://doi.org/10.1111/1468-0262.00467

Minetti, R., \& Zhu, S. (2011). Credit Constraints and Firm Export: Microeconomic Evidence from Italy. Journal of International Economics, 83, 109-125.

https://doi.org/10.1016/j.jinteco.2010.12.004

Muuls, M. (2015). Exporters and Credit Constraints: A Firm Level Approach. Journal of 
International Economics, 95, 333-343. https://doi.org/10.1016/j.jinteco.2014.12.003

Wagner, J. (2014). Credit Constraints and Exports: a Survey of Empirical Studies Using Firm-level Data. Industrial and Corporate Change, 23, 1477-1492.

https://doi.org/10.1093/icc/dtu037

Wagner, J. (2014). Credit constraints and exports: evidence for German manufacturing enterprises. Applied Economics, 46, 294-302. https://doi.org/10.1080/00036846.2013.839866

\section{Copyright Disclaimer}

Copyright for this article is retained by the author(s), with first publication rights granted to the journal.

This is an open-access article distributed under the terms and conditions of the Creative Commons Attribution license (http://creativecommons.org/licenses/by/3.0/). 